Original Research Article

\title{
Drug utilization study in neonatal intensive care unit of a tertiary care teaching hospital
}

\author{
Jayeshkumar P. Vaghela ${ }^{1}$, Anupama Sukhlecha ${ }^{2 *}$
}

\author{
${ }^{1}$ Clinical Pharmacologist, \\ Ontario, Canada \\ ${ }^{2}$ Department of Pharmacology, \\ M P Shah Govt. Medical \\ College, Jamnagar, Gujarat, \\ India
}

Received: 11 August 2017 Accepted: 04 September 2017

\section{*Correspondence to: \\ Dr. Anupama Sukhlecha, Email: anupama_acad@ yahoo.co.in}

Copyright: (C) the author(s), publisher and licensee Medip Academy. This is an openaccess article distributed under the terms of the Creative Commons Attribution NonCommercial License, which permits unrestricted noncommercial use, distribution, and reproduction in any medium, provided the original work is properly cited.

\begin{abstract}
Background: Sick and pre-term neonates are admitted in neonatal intensive care units (NICU) and treated. A great care needs to be taken to use drugs in neonates due to the immaturity of their body functions. There is a lack of standard drug prescribing guideline in children, especially neonates because; safety and efficacy for a majority of drugs have not been established in them. The objectives of the study were to evaluate the drug utilization pattern in NICU of a teaching hospital and to identify problems in drug utilization and suggest measures, if needed.

Methods: A prospective, observational study was carried out in NICU for duration of one year. Demographic details like age, sex, birth weight, duration of hospitalization was recorded from the case files of neonates. The morbid condition, treatment with drugs and other supportive modalities were recorded. The outcome of treatment was also noted. WHO drug utilization core indicators were also evaluated.

Results: Out of 623 admissions in NICU, 56\% were males. There were $56 \%$ of neonates who were born pre-term. The maximum used drugs were Vitamin $\mathrm{K}$ $(73 \%)$ and antibiotics $(64 \%)$. The antibiotics were mainly from penicillin and aminoglycoside groups. Respiratory distress syndrome (19\%) and neonatal sepsis (16\%) were the most common causes for admission. Out of total admissions, $64 \%$ were discharged following recovery, while, $12 \%$ had expired.

Conclusions: Drugs usage in neonates should be minimal and should be prescribed from essential drug list. Antibiotic policy needs to be formulated for hospitals to minimize antibiotic usage and prevent development of resistance.
\end{abstract}

Keywords: Antibiotics, Drug utilization, Essential medicine list, Neonates, Rationality

\section{INTRODUCTION}

Essential drugs are those that satisfy the health care needs of a majority of population; they should therefore be available at all times in adequate amounts and in appropriate dosage forms and at a price that individuals and the community can afford. This concept is intended to be flexible and adaptable to many different situations; exactly which drugs are regarded as essential remains a national responsibility. ${ }^{1}$ World Health Organization (WHO) defines drug utilization as "the marketing, distribution, prescription and use of drugs in a society with special emphasis on resulting medical, social and economic consequences". The principal aim of drug utilization research is to facilitate rational use of drugs in the population. ${ }^{2}$

Neonates are a very vulnerable group to adverse drug reactions due to immaturity of their body functions. So, great care needs to be taken to prescribe drugs to them. Recent advances in prenatal care have resulted in an increase in drug exposure rates in pregnant mothers, causing infants to be exposed to aptitude of different drugs, even when in utero. Advances in medical technology have also resulted in improved survival rates in both term and preterm infants, including high risk and low birth weight infants. Because of these changes in the medical 
management of the newborn, drug exposure patterns in infants have also changed. ${ }^{3}$ Most drug inserts contain precautionary disclaimer for usage in children because, safety and efficacy in children have not been established.

There are some irrational drug combinations which are also being used in hospitals which do not satisfy the essential medicine list of our country. Such irrational preparations can cause severe adverse drug reactions to patients. So, it is important to decrease use of irrational drugs by using essential drugs.

A growing number of pharmaceutical products are available on the world market and there has been an increase both in the consumption of the drugs and in expenditure on them. In spite of this, many people throughout the world cannot obtain the drugs they need. There are also many people who have access to drugs but do not get the right drug in the right dosage when they need it. Irrational prescription of drug is of common occurrence in clinical practice, important reason being lack of knowledge about drug and unethical drug promotion. Monitoring of prescriptions and drug utilization studies could identify the associated problems and provide feedback to prescribers. ${ }^{2}$

Most newborns are exposed to a number of drugs many of the times. Most of the reported drug utilization studies have been carried out in adult patients with only a few being reported from children, especially neonates. So the present study has been taken up with the purpose of generating some valid data and useful information for improving the quality of neonatal care. Developing countries have limited funds available for health care and drugs so it becomes very important to prescribe drugs rationally so that the available funds can be utilized optimally. ${ }^{4}$

\section{METHODS}

This study was carried out to evaluate the drug utilization pattern in neonatal intensive care unit (NICU). It was a prospective, observational study conducted at NICU under Paediatrics department of Guru Gobind Singh Government Hospital attached with the M. P. Shah Medical College, Jamnagar, Gujarat, India. The study was carried out for duration of one year (from December 2013 to November 2014) on 623 inpatients at NICU. Permission was obtained from the Head of Department of Paediatrics prior to commencement of the study. All patients of either sex admitted to NICU were included in the study. Neonates who were discharged or who died within 24 hours of NICU admission were excluded from the study.

\section{Sample size}

WHO recommendation on sample size is that there should be at least 600 encounters included in cross-sectional survey describing current treatment practices. $^{5}$

\section{Collection of data}

Data of patients matching inclusion criteria was recorded. Demographic details like: name, age, sex, diagnosis, ongoing treatment was recorded from patient's case file. This data was recorded in a previously prepared case record form. The generic name of the drugs and the generic contents of formulation were obtained from the Indian Drug Review, January-February, $2015 .^{6}$

\section{Data was further analyzed as under}

- $\quad$ Age and sex wise distribution

- Morbidity pattern

- Prescribing frequency of drugs

- Average number of drugs per encounter

- Percentage of encounters with an antibiotic prescribed

- Percentage of encounters with an injection prescribed

- Percentage of drugs prescribed by generic name

- Percentage of drug prescribed from Essential drug list formulary

\section{Statistical analysis}

Recorded data was analyzed by Microsoft Office Excel 2007 and using descriptive statistics. Wherever necessary, the results were depicted in the form of percentages and graphs.

\section{RESULTS}

In the present study, we have collected data of 623 neonates admitted in NICU over a period of one year. The observation and results of our study are as follows:

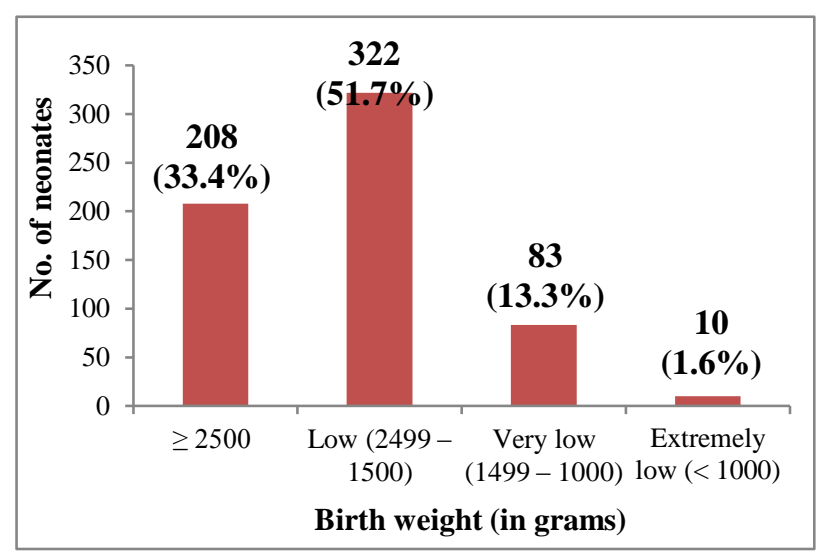
Figure 1: Birth weight distribution of neonates
admitted $(n=623)$.

The age and sex distribution of neonates admitted was: A majority of neonates $536(86.3 \%)$ were in early neonatal period ( $<7$ days), while $87(13.7 \%)$ were in late neonatal period. A majority of patients admitted in NICU were male $348(55.85 \%)$. The gestational age distribution in NICU was: Preterm 349 (56\%), followed by term neonates 263 $(42.2 \%)$ and post-term neonates $11(1.8 \%)$. The birth 
weight distribution in NICU is shown in Figure 1. The mean \pm SD of weight of all patients admitted in NICU was $2.16 \pm 0.61 \mathrm{~kg}$.

The morbidity pattern observed in NICU is shown in Table 1. The prescribing frequency of drugs is shown in Table 2 . The drugs prescribed with a frequency of less than five percent are shown in Table 3. Paracetamol injection was prescribed in 28 neonates, caffeine in 3 and nasal saline drops in 3 neonates respectively.

\section{Table 1: Morbidity pattern observed in neonatal intensive care unit $(n=623)$.}

\begin{tabular}{|ll|}
\hline Morbid condition & Frequency (\%) \\
\hline Respiratory distress syndrome & $117(18.8 \%)$ \\
\hline Neonatal sepsis & $101(16.2 \%)$ \\
\hline Low birth weight & $96(15.4 \%)$ \\
\hline Neonatal hyper-bilirubinaemia & $90(14.4 \%)$ \\
\hline Birth asphyxia & $70(11.2 \%)$ \\
\hline Meconium aspiration syndrome & $40(6.4 \%)$ \\
\hline HbsAg positive mother & $23(3.7 \%)$ \\
\hline Others & $86(13.8 \%)$ \\
\hline
\end{tabular}

Table 2: Most frequently prescribed drugs in neonatal intensive care unit $(n=623)$.

\begin{tabular}{|lll|}
\hline Groups & Name of drug & Frequency (\%) \\
\hline \multirow{4}{*}{ Antibiotics } & Ampicillin & $203(32.6 \%)$ \\
\cline { 2 - 3 } & Gentamicin & $201(32.3 \%)$ \\
\cline { 2 - 3 } & Amikacin & $198(31.8 \%)$ \\
\cline { 2 - 3 } Vasopressors & Cefotaxime & $183(29.4 \%)$ \\
\cline { 2 - 3 } & Metronidazole & $91(14.6 \%)$ \\
\hline Antiepileptics & Adrenaline & $71(11.4 \%)$ \\
\hline \multirow{5}{*}{ Vopamine } & $41(6.6 \%)$ \\
\hline \multirow{2}{*}{ others } & Phenobarbitone & $56(8.9 \%)$ \\
\cline { 2 - 3 } & $\begin{array}{l}\text { Calciumin K } \\
\text { gluconate }\end{array}$ & $454(72.9 \%)$ \\
\cline { 2 - 3 } & $\begin{array}{l}\text { Syrup Simyl } \\
\text { MCT (Carnitine) }\end{array}$ & $68(104(16.7 \%)$ \\
\cline { 2 - 3 } & $\begin{array}{l}\text { Syrup Evion } \\
\text { (Vitamin E) }\end{array}$ & $43(6.9 \%)$ \\
\cline { 2 - 3 } & $\begin{array}{l}\text { Syrup Hovite } \\
\text { (Multivitamin) }\end{array}$ & $38(6.1 \%)$ \\
\cline { 2 - 3 } & $\begin{array}{l}\text { Syrup } \\
\text { Paracetamol }\end{array}$ & $41(6.6 \%)$ \\
\hline
\end{tabular}

The other supportive modalities used in NICU were: Isolyte- $\mathrm{P}$ in $261(41.9 \%)$ neonates and oxygen in 200 (32.1\%) neonates. Other fluids, namely dextrose 5\%, dextrose $10 \%$, dextrose normal saline, normal saline was used in 249 (39.9\%) neonates. Phototherapy was given in $100(16.1 \%)$, surfactant therapy in $62(9.9 \%)$ and exchange transfusion in $5(0.8 \%)$ neonates respectively.

The percentage of encounters with an antibiotic prescribed is shown in Table 4. Most of the neonates $353(56.7 \%)$ were prescribed at least two antibiotics. Culture sensitivity testing was found positive in $87(13.9 \%)$ patients. Out of these, change in antibiotic was done in 40 patients, while the others were given the same treatment. The most common organisms found were E. coli (40), Klebsiella (16) and Pseudomonas (14).

\section{Table 3: Drugs prescribed with a frequency of less than five percent $(n=623)$.}

\begin{tabular}{|c|c|c|}
\hline Group & Name of drug & Frequency \\
\hline \multirow{9}{*}{ Antibiotics } & Ceftazidime & 19 \\
\hline & Ceftriaxone & 12 \\
\hline & $\begin{array}{l}\text { Amoxicillin+ } \\
\text { Clavulanic acid }\end{array}$ & 6 \\
\hline & Vancomycin & 6 \\
\hline & Levofloxacin & 9 \\
\hline & Ciprofloxacin & 18 \\
\hline & $\begin{array}{l}\text { Piperacillin+ } \\
\text { Tazobactam }\end{array}$ & 4 \\
\hline & Neomycin powder & 6 \\
\hline & $\begin{array}{l}\text { Tobramycin eye } \\
\text { drops }\end{array}$ & 2 \\
\hline \multirow{2}{*}{ Antiepileptics } & Phenytoin & 12 \\
\hline & Lorazepam & 10 \\
\hline \multirow{2}{*}{ Ionotropics } & Digoxin & 2 \\
\hline & Dobutamine & 25 \\
\hline Bronchodilators & Aminophylline & 16 \\
\hline Prokinetic & Domperidone drops & 1 \\
\hline Diuretic & Furosemide & 2 \\
\hline \multirow{4}{*}{$\begin{array}{l}\text { Vaccines and } \\
\text { immunoglobulins }\end{array}$} & Hepatitis B vaccine & 23 \\
\hline & $\begin{array}{l}\text { Hep. B } \\
\text { immunoglobulin }\end{array}$ & 23 \\
\hline & Tetanus injection & 10 \\
\hline & $\begin{array}{l}\text { Tetanus } \\
\text { immunoglobulin }\end{array}$ & 2 \\
\hline \multirow{3}{*}{ Others } & Ranitidine injection & 23 \\
\hline & $\begin{array}{l}\text { Syrup Calcium } \\
\text { carbonate }\end{array}$ & 16 \\
\hline & Syrup Ibuprofen & 3 \\
\hline
\end{tabular}

The average number of drugs per encounter is shown in Table 4. The total number of drugs prescribed was 2766 in 623 encounters. Percentage of encounters with injections prescribed shown in Table 4. The percentage of drugs prescribed from list of essential medicines is shown in Table 4. The table includes the number of drugs prescribed from national list of essential medicines of India (NLEMI), 2011. ${ }^{[7]}$ It also includes drugs from WHO model list of essential medicines for children, 2013. ${ }^{[8]}$ The percentage of drugs prescribed by generic name is shown in Table 4 . There were 2350 out of 2766 drugs that were prescribed by generic name.

The duration of hospitalization of neonates is shown in Figure 2. The mean \pm SD of length of hospital stay for all the patients was $4.97 \pm 1.41$ days. The outcome of neonates following hospitalization was: 398 (63.9\%) neonates were 
discharged, 74 (11.9\%) neonates expired and $151(24.2 \%)$ neonates left against medical advice (LAMA). The most common cause for death was respiratory distress syndrome in $36(48.6 \%)$ neonates, followed by birth asphyxia in 22 $(29.8 \%)$ neonates.

\section{Table 4: WHO core indicators evaluated in neonatal intensive care unit $(n=623)$.}

\begin{tabular}{|lc|}
\hline WHO core indicator & Value \\
\hline $\begin{array}{l}\text { Average number of drugs prescribed per } \\
\text { encounter }\end{array}$ & $4.43 \%$ \\
\hline $\begin{array}{l}\text { Percentage of encounters resulting in the } \\
\text { prescription of an antibiotic }\end{array}$ & $64.7 \%$ \\
\hline $\begin{array}{l}\text { Percentage of encounters resulting in the } \\
\text { prescription of an injection }\end{array}$ & $95.2 \%$ \\
\hline $\begin{array}{l}\text { Percentage of drugs prescribed by generic } \\
\text { name }\end{array}$ & $84.9 \%$ \\
\hline $\begin{array}{l}\text { Percentage of drugs prescribed from WHO } \\
\text { EML (children) 2013\# }\end{array}$ & $69.4 \%$ \\
\hline $\begin{array}{l}\text { Percentage of drugs prescribed from NLEMI } \\
\text { 2011\#\# }\end{array}$ & $71.4 \%$ \\
\hline
\end{tabular}

\#WHO EML: World Health Organization Essential Medicine List for children

\#\#NLEM: National List of Essential Medicines of India

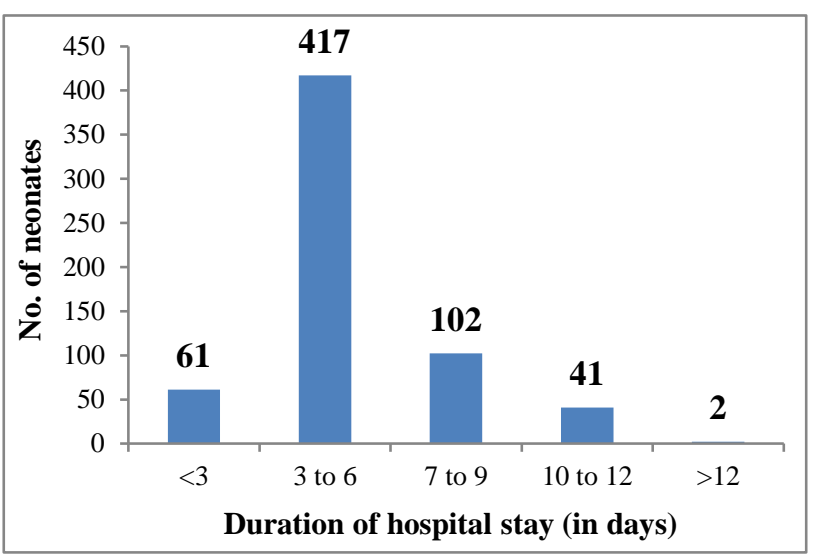

Figure 2: Duration of hospitalization of neonates $(n=623)$.

\section{DISCUSSION}

There was a male predominance $(55.9 \%)$ in our study which is consistent with another study in which $62.1 \%$ of patients were male. ${ }^{9}$ In another study, male neonate admission was $58 \%$, which is quite comparable to our study. ${ }^{10}$ The gender discrimination in terms of access to healthcare is apparent in the study. There is an urgent need to create awareness against gender discrimination, which begins at an early age. ${ }^{11}$

In our study, $86.3 \%$ patients were admitted in early neonatal period. This is similar to a study in which patients admitted in early neonatal period were $82 \% .{ }^{12}$ The mean age of neonates was $3.23 \pm 4.0$ days. A neonate is particularly vulnerable to adverse influences like asphyxia, infection, complications of preterm birth etc. during early neonatal days and requires special attention. ${ }^{13}$

A majority of neonates in our study were preterm $(56 \%)$ which is comparable to another study $(54.6 \%) .{ }^{14} \mathrm{~A}$ significantly large number of neonates $(51.7 \%)$ were of low birth weight in our study. The mean birth weight was $2.16 \pm 0.61 \mathrm{~kg}$ in our study which is in accordance with a study where it was $2250 \pm 96.8 \mathrm{~g}$ and in yet another study as $2498 \pm 1000 \mathrm{gm} .{ }^{3,15}$ Low birth weight (LBW) infants remain vulnerable to malnutrition, recurrent infections, neurodevelopmental disabilities and have high mortality. ${ }^{11}$

A majority of neonates admitted in NICU were of respiratory distress syndrome $(18.8 \%)$ and neonatal sepsis (16.2\%) followed by low birth weight, neonatal jaundice, birth asphyxia and meconium aspiration syndrome. In one study, the major causes of admission were sepsis (29.2\%) and low birth weight $(23.4 \%)$ followed by birth asphyxia, neonatal jaundice and meconium aspiration syndrome while in another study the largest number of neonates was in the premature category $(78.5 \%)$, birth asphyxia (36.2\%), jaundice $(28.8 \%)$ and respiratory distress $(24.8 \%){ }^{12,15}$ Neonatal sepsis is a major cause for admission to NICU because most of the neonates admitted are preterm and have low birth weight. They are particularly susceptible for sepsis and infection from mother during birth.

In the present study, most commonly prescribed drugs were Vitamin K (72.9\%) and antibiotics, followed by antiprotozoals, vasopressors, anti-epileptics and vitamins. The total encounters with an antibiotic prescribed were 402 , which account for $64.5 \%$ of total encounters. A majority of neonates $(56.7 \%)$ received at least two antibiotics. Higher incidences of antibiotic exposure in NICU could be due to the common practice of prescribing antibiotics without waiting for outcome of bacterial culture due to seriousness of illness in neonates (empirical usage). The most commonly prescribed antibiotics were ampicillin (32.6\%), gentamicin $(32.3 \%)$, amikacin $(31.8 \%)$ and cefotaxime (29.4\%). In another study, $62 \%$ neonates received amikacin, $44 \%$ penicillin and $38 \%$ cefotaxime respectively. [15] In yet another study, 94.2\% of neonates received ampicillin and $92.2 \%$ received cefotaxime. [3] Similar findings were observed in other studies in which penicillins and aminoglycosides were commonly prescribed antibiotics. ${ }^{14,16,17}$

Out of 402 encounters with antibiotic prescribed, antibiotics were changed in 40 patients in whom only 15 patients were culture sensitivity positive. While in rest of the patients, no change in antibiotic regimen was found even if culture sensitivity test reports were positive. The reason may be improvement in patient's condition with ongoing drugs. In our study, the most common organisms in infective conditions were gram-negative organisms. Most common organisms found in our study were $E$. coli (40), Klebsiella (16) and Pseudomonas (17), which is in accordance with other studies done where Klebsiella and E.coli were the most common organisms. ${ }^{18,19}$ In our study, 
antibiotics were changed to cefotaxime, amikacin from ampicillin, gentamicin in case of E.coli and Klebsiella according to their sensitivity pattern. While in case of Pseudomonas, ceftazidime and piperacillin were prescribed. Another study reports that ampicillin and gentamicin may no longer be effective for the treatment of neonatal sepsis as $71 \%$ Klebsiella and $50 \%$ E. coli were reported resistant to gentamicin. ${ }^{[20]}$ Inappropriate use of antibiotics leads to emergence of resistance. So, antibiotic surveillance is mandatory to optimize antibiotic therapy especially in culture negative patients with infection like symptoms. $^{21}$

In our study utilization of vitamin $\mathrm{E}$, multivitamin, carnitine and calcium gluconate was $6.9 \%, 6.1 \%, 10.9 \%$, $16.7 \%$ respectively. This is in accordance with another study in which it was $91 \%, 40 \%, 43 \%, 42 \%$ respectively. ${ }^{15}$ Vitamin K deficiency bleeding is of particular concern in neonates as they are born with low levels of Vitamin K. Current recommendations suggests that single intramuscular administration of Vitamin $\mathrm{K}$ is an effective, safe and sustainable approach of preventing VKDB (Vitamin K deficiency bleeding). ${ }^{22}$ Several studies suggest an improvement of fatty acid oxidation if total parenteral nutrition (TPN) is supplemented with L-carnitine. ${ }^{23}$

Clinical trials have validated the efficacy of phototherapy in reducing excessive unconjugated hyperbilirubinemia and its implementation has drastically curtailed the use of exchange transfusions. ${ }^{24}$ Phototherapy has also been used for neonates in our NICU (16\%). Respiratory failure secondary to surfactant deficiency is a major cause of morbidity and mortality in low birth weight immature infants. The usage of surfactants was $9.9 \%$ in our study. Surfactant therapy substantially reduces mortality and respiratory morbidity in neonates. ${ }^{13}$

The average number of drugs prescribed per encounter was 4.43 in our study. It could be due to shorter duration of stay of neonates in NICU. A study reported average number of drugs per encounter as 4.8 which is quiet comparable with our study. ${ }^{25}$ Another study reported mean drug usage as 3.6 drugs per infant. ${ }^{3}$ However, other studies reported mean drug usage as 7 and 11.1 drugs per neonate respectively. ${ }^{14,15}$ In our study, total encounters with an injection prescribed were $593(95.2 \%)$. Similar findings were observed in another study where in intravenous route was the most common route of drug administration $(92.1 \%) .{ }^{25}$ Parental route is commonly seen in NICU and it plays important role in management of sick neonates until they can tolerate enteral/oral feeding. ${ }^{13}$

In our study, $71.4 \%$ of the drugs were prescribed from the national list of essential medicines in India (NLEMI), 2011. Another study reports that $88.6 \%$ drugs were prescribed in compliance with NLEM, 2003. ${ }^{25}$ Out of 49 drugs used in our study, 34 were from WHO model list of essential medicine for children, 2013. Thus $69.38 \%$ of the drugs were prescribed according to WHO Model List of Essential Medicine for Children, 2013. This could be due to multiple factors for e.g., availability of drugs and clinician's preference. In our study $85 \%$ drugs were prescribed by generic name, which is appreciable. Another study reported that $79.7 \%$ drugs were prescribed by generic name. ${ }^{25}$ Increasing generic prescribing would rationalize the use and reduce the cost of drugs.

Average length of stay in NICU for all patients being admitted was $4.97 \pm 1.41$ days. This result is not in accordance with other studies where mean length of NICU stay were 15 days, 19.4 days and 17 days respectively. $3,14,15$ Thus in our study average length of stay at NICU was less as compared to the above studies could be due to death of neonates and those who had left against medical advice. In our study, $63.9 \%$ neonates were discharged, $11.9 \%$ expired and $24.2 \%$ neonates left against medical advice. The most common causes for death were respiratory distress syndrome (48.6\%) followed by birth asphyxia (29.7\%). In another study, $71.54 \%$ neonates were discharged, $7.08 \%$ had died and $14.87 \%$ had left against medical advice. ${ }^{26}$ In yet another study, $48.5 \%$ neonates were discharged, $25.9 \%$ had died and $25.9 \%$ had left against medical advice. ${ }^{9}$ Increase in death rate at NICU may be due to admission of neonates either from different hospitals or from neonates delivered at home especially with severe infections and morbidities. Precautionary measures like antenatal monitoring of high-risk pregnancies, timely referral and resuscitation at the time of birth can reduce mortality. ${ }^{27}$

The strength of our study is that, it is a step further in the broader evaluation of safety and efficacy of drug prescriptions in NICU of a teaching hospital. The limitation of our study is that the sample size is small and it is restricted to a government teaching hospital.

\section{CONCLUSION}

To conclude, there should be rational usage of drugs in neonates because of their immature body functions and to avoid adverse drug reactions. The drugs should be mainly prescribed from essential medicine list. There is a need of antibiotic policy for the hospital to minimize antibiotic usage and prevent the development of resistance. Therapeutic treatment guidelines need to be formulated in hospital to rationalize drug usage.

\section{ACKNOWLEDGEMENTS}

Authors would like to thank the head of the Department of Paediatrics for permitting to conduct the study. Authors are also grateful to the residents and nursing staff posted in NICU for help during the study.

Funding: No funding sources Conflict of interest: None declared

Ethical approval: The study was approved by the Institutional Ethics Committee 


\section{REFERENCES}

1. The use of essential drugs. Ninth report of the WHO Expert Committee. Geneva, World Health Organization, 2000 (WHO Technical Report Series, No. 895)

2. Introduction to Drug Utilization Research. Oslo: World Health Organization. Chapter 1. What is drug utilization research and why is it needed; 2003:8-12.

3. Warrier I, Wei D, Girija N, Salari V, Aranda J. Patterns of Drug Utilization study in Neonatal Intensive care unit. J Clin Pharmacol. 2006;46:449-55.

4. Shankar PR, Partha P, Dubey AK, Mishra P, Deshpande VY. Intensive care unit drug utilization in a teaching hospital in Nepal. Kathmandu Uni Med J. 2005;3(10):130-7.

5. World Health Organization. How to investigate drug use in health facilities: Selected drug use indicators. World Health Organization. Chapter 2, Core drug use indicators; 1993:12-24.

6. Desai S. Editor. Indian Drug Review-triple I. CMP Medica India Pvt Limited, Bangalore, India; 2015:1.

7. National List of Essential Medicines of India. 2011;1123. Available at: https://www.nhp.gov.in/nationallist-of-essential-medicines-2011_pg [Last accessed on 2017 August 12]

8. Medicines WHO. WHO model list of essential medicines for children 2013; 1-35. Available at: http://www.who.int/medicines/publications/essential medicines/18th_EML.pdf [Last accessed on 2017 August 12]

9. Parkash J, Das N. Pattern of admissions to neonatal unit. J Coll Physicians Surg Park. 2005;15(6):341-4.

10. Narayan R. A study of the pattern of admissions and outcome in a neonatal intensive care unit at high altitude. Sri J Child Health. 2012;41(2):79-81.

11. Dhanraj G, Francis R, Srinivas R. Morbidity and mortality patterns of neonatal emergency in Gujarat Case study of GVK EMRI. Available at: http://www.emri.in/images/stories/Morbidity\%20and $\% 20$ mortality\%20patterns.pdf. [Last accessed on 2017 August 12]

12. Rakhia A, Khan M, Memon AA, Dahar SA. Pattern and outcome of neonatal ailments in a tertiary care hospital. Pak J Med Res. 2014;14(1):14-6.

13. Kliegman RM, Behrman RE, Jenson HB, Stanton BF. Nelson Textbook of Pediatrics, 18th Ed. New Delhi: Elsevier Publication. Chapter 97. The High Risk Infant; 2008:701-708.

14. Neubert A, Lukas K, Leis T, Dormann H, Brune K, Rascher W. Drug utilisation on a preterm and neonatal intensive care unit in Germany: a prospective, cohortbased analysis. Eur J Clin Pharmacol. 2010;66:87-95.
15. Uppal R, Chhabra A, Narang A. Pattern of Drug Use in neonatal intensive care unit. Indian Pediatr. 1998;35:647-9.

16. Clark RH, Bloom BT, Spitzer AR, Dale RG. Reported medication use in the neonatal intensive care unit: Data from a large national data set. J Pediatr. 2006;117(6):1979-87.

17. Lesko SM, Epstein MF, Mitchell AA. Recent patterns of drug use in newborn intensive care. J Pediatr. 1990;116:985-90.

18. Jain NK, Jain VM, Maheshwari S. Clinical profile of neonatal sepsis. Kathmandu Univ Med J. 2003;1(2):117-20.

19. Monsef A, Eaghbalian F. Antibiotic sensitivity pattern of common bacterial pathogens in NICU and neonatal ward in Hamedan province of Iran. Health. 2010;2(6):625-29.

20. Zaidi AK, Huskins WC, Thaver D, Bhutta ZA, Abbas Z, Goldmann DA. Hospital acquired neonatal infections in developing countries. Lancet. 2005;365:1175-88.

21. Stocker M, Ferrao E, Banya W, Cheong J, Macrae D, Furck A. Antibiotic surveillance on a pediatric intensive care unit: easy attainable strategy at low costs and resources. BMC Pediatr. 2012;12:196.

22. Child Health Division, Ministry of Health and Family Welfare, Government of India. Operational Guidelines: Injection Vitamin K Prophylaxis at Birth (in facilities). Available at: http://tripuranrhm.gov.in/Guidlines/3006201401.pdf [Last accessed on 2017 August 12]

23. Schmidt-Sommerfeld E, Penn D. Carnitine and total parenteral nutrition of the neonate. Biol Neonate. 1990;58(1):81-8.

24. Bhutani VK. Phototherapy to prevent severe neonatal hyperbilirubinemia in the newborn infant 35 or more weeks of gestation. Paediatr. 2011;128(4).

25. Chatterjee S, Mandal A, Lyle N, Mukherjee S, Singh AK. Drug utilization study in a neonatology unit of a tertiary care hospital in eastern India. Pharmacoepidemiol Drug Safety. 2007;10:1141.

26. Rahim F, Jan A, Mohummad J, Iqbal H. Pattern and outcome of admissions to neonatal unit of Khyber teaching hospital, Peshawar. Pak J Med Sci. 2007;23(2):249-53.

27. Chishty AL, Iqbal A, Anjum A, Maqbool S. Spectrum of multiorgan systemic involvement in birth asphyxia. Pak J Pathol. 2001;12:81-7.

Cite this article as: Vaghela JP, Sukhlecha A. Drug utilization study in neonatal intensive care unit of a tertiary care teaching hospital. Int J Basic Clin Pharmacol 2017;6:2510-5. 